\title{
Innovative development of the region through the formation of a technological cluster
}

\author{
Svetlana Lapteva ${ }^{1, *}$ \\ ${ }^{1}$ Moscow State University of Civil Engineering, Yaroslavskoye shosse, 26, Moscow, 129337, Russia
}

\begin{abstract}
The issues of creation and functioning of technology parks, the development of innovative policies of the state, the problems of implementing innovative projects in the construction industry are discussed in the paper. Some statistical data reflecting the degree of development of this form of stimulating society to innovative development are presented. The author gives recommendations to facilitate the process of transferring the construction industry to an innovative path of development, as well as solving a number of emerging economic problems.
\end{abstract}

\section{Introduction}

In the past few years, the topic of developing a national innovation system is of great practical interest. Throughout the world, the cooperation of scientific institutes and organizations, universities, state authorities and business is recognized as the most important factor on the path to the effective functioning of the innovation system and technological progress. In our country, this interaction has not yet been properly developed, but recently there has been a tendency to organize such cooperation by creating new zones of innovative and technological development in the form of high-tech parks. This explains the relevance of the chosen research topic. The aim of the study is to identify problems in the development of the construction industry at the present stage by attracting knowledgeintensive technological innovation territories, such as technology parks in the regions of Russia. The author has identified a number of problems appearing in the construction sector as a result of ongoing legislative changes. The main possible solutions of these problems are proposed in this study. Given the global trends, the author justified increasing interest in the creation and functioning of technology parks in Russia, dictated by the legislatively accepted Strategy for scientific and technological development of the country [1].

\section{Materials and methods}

\footnotetext{
* Corresponding author: magiclife@inbox.ru
} 
For scientific research, legal acts, state and regional standards, methodological recommendations, normative and technical documentation on the creation and functioning of technology parks, development and implementation of innovative solutions were used. The published proceedings of scientific and practical research of both domestic and foreign authors were used. The dialectic research method was chosen as the main one. Standard methods for assessing and analyzing data were also used.

First, an analysis of domestic and foreign studies on the identified problem was made, then, based on the identified patterns and taking into account the norms of domestic standards and the legal framework, the impact of innovation policy on the development of technology parks was assessed. An assessment of the ways of commercializing innovations was made, problems were identified, and ways to solve them were proposed to eliminate factors that impede the development of Russia's innovative potential.

The author found that it is technology parks that are of great interest in Russia today, despite the fact that they can include different types of high-tech parks. Since they represent a high concentration of scientific minds from various fields, innovative products and developments, new technologies and specialized equipment, it is nothing more than one of the tools for shaping the country's innovative economy.

According to observations of the development of technology parks in global practice, experience has shown that to create and "launch" a technology park, bringing an object to the stage of stable operation requires from 6 to 10 years. Moreover, as noted by V.A. Barinova, V.A. Kotsyubinsky, A.R. Mukhlisova, V.V. Rybalkin: "Recognized success comes in $30-40$ years".

The minimum area of the technology park is $10,000 \mathrm{~m}^{2}$. However, for example, in Moscow and the Moscow region, this indicator significantly exceeds this lower threshold.

Of course, it is quite expensive for any business to maintain such areas, to ensure their compliance with all the requirements for them. Especially when it comes to the fact that several years are allotted for the formation period, and serious results will have to wait for several decades more. At the same time, it is required to confirm the status of a technology park every 10 years from the moment of its receipt. It becomes quite obvious that without state participation, given the history of our country's economic development and the relatively recent transition to market relations, the number of existing technology parks would be extremely small today. In general, judging by the statistics and analysis of the regulatory and legislative framework, the state is actively investing in innovative development (Fig. 1). 


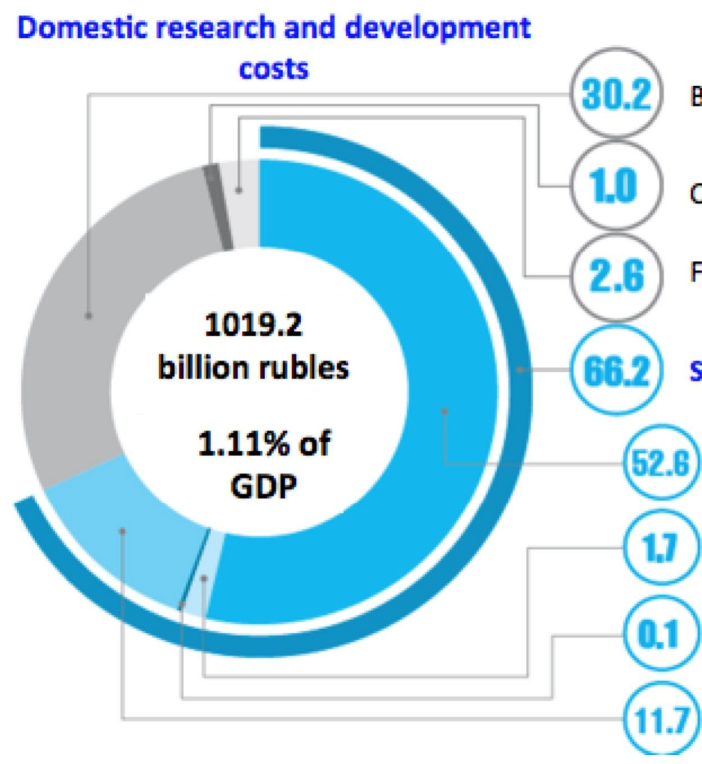

\section{Sources of financing, \%}

Business sector funds

Other national sources

Foreign sources

State funds

Federal budget

Funds of the budgets of constituent entities of the Russian Federation and local budgets

Budget appropriations for the maintenance of educational institutions of higher education

Funds of public sector organizations (including their own)

Fig. 1. Financing of research and development in Russia, according to statistics for 2017.

According to statistics for the end of 2017, research and development financing in Russia was carried out from federal budget in more than 50\% of cases. Moreover, priority was given to the development of life sciences and the industry of nanosystems (Fig. 2).

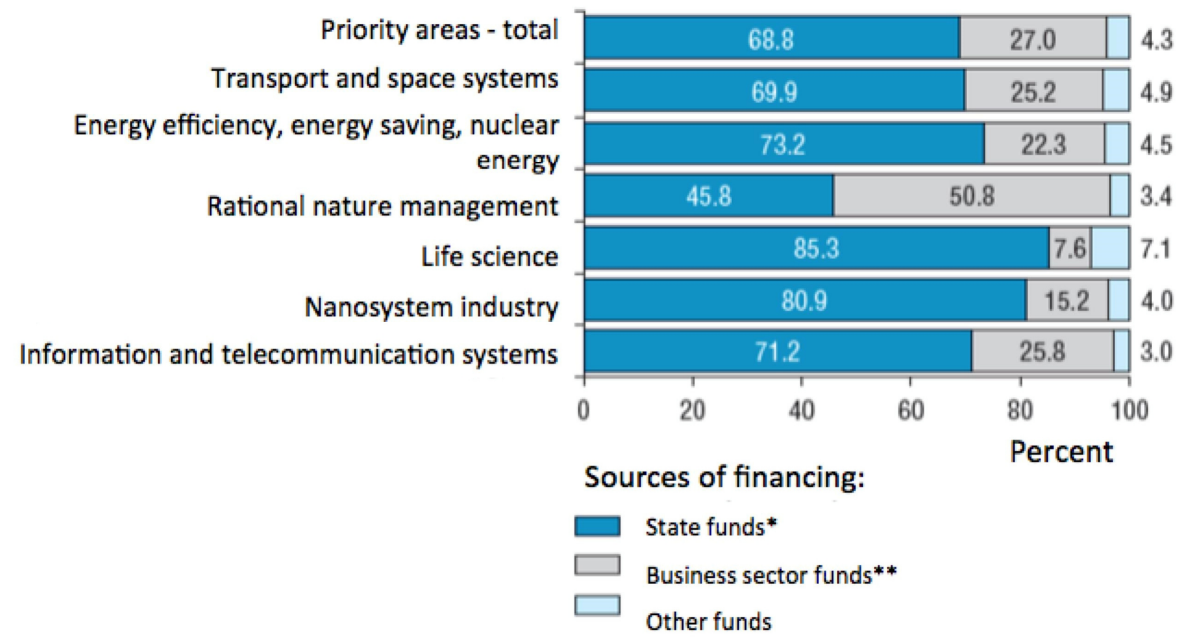

* Including budgetary funds and funds of public sector organizations (including their own). ** Funds of business sector organizations (including their own).

Fig. 2. The structure of internal costs for research and development in priority areas of the development of science, technology and engineering and sources of financing, according to statistics for 2017.

A rather interesting fact is that the state willingly invests budget funds in the development of industrial production and does not invest at all in innovations in the construction industry, it is $100 \%$ given to business (Fig. 3). 


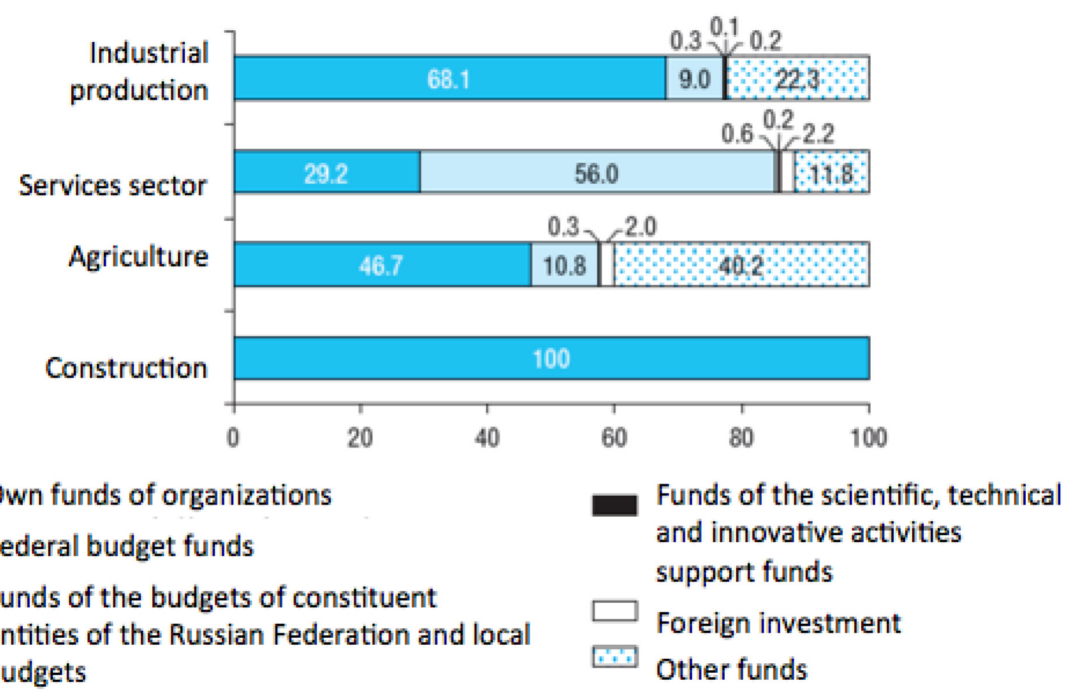

Fig. 3. Costs of technological innovation by sources of financing, in\%, according to statistics for 2017.

Analyzing the development of the construction industry, it would be important to note the fact that changes taking place in the construction sector and planned in the future with a view to its development in accordance with the Strategy for the development of the construction industry until 2030, adopted by the state, show us certain emerging trends, specifically: the desire to increase the level of competencies of the labor resources involved in the construction sector and significantly reduce the number of developers while increasing the transparency of their activities and the transition of many building processes in a digital format. At the same time, the leadership of the country is striving to increase the living conditions of the population, increase the percentage of housing provision, and for these purposes, the task has been set to bring the volume of housing construction to at least 120 million square meters a year by 2024. In this case, a particular attention should be paid to the fact that in an effort to be in congruence with the developed European countries on the formal basis of provision with square meters per 1 person, the quality indicator is not taken into account, no criteria for assessing the quality of construction are mentioned. Traditionally, it is believed that homebuilding in Europe is better than in Russia. Today, when during the period of rapid development of information technologies and the active growth of innovation, opportunities for the rapid exchange of experience and for conducting scientific research of almost any complexity, we have every opportunity to bring the construction industry to a whole new level, but these opportunities are not used to the full. At the same time, as shown by studies of residents of industrial parks in Russia, most of them (20\%) are employed in the construction sector, as well as in the production of building materials and structures, consumables, tools and equipment to support the construction industry. Today, there are several varieties of technology parks, but industrial parks are a slightly different territory. The main and fundamentally important detail in their differences is that industrial parks are created in order to work with traditional industry, and technology parks are aimed at work obligatory related to the development of high technology, innovative developments and the creation of startups. In the already existing technology parks, enterprises of the construction industry are almost not represented. Thus, we see that work in the area of innovative development of the construction industry is not actually stimulated, which means it is fair to assume that building up the pace of 
construction will not lead to a noticeable increase in its quality. In this case, there are big risks to repeat the history of the development of domestic homebuilding in the post-war period: to get large volumes of commissioned housing, which in a short time will cease to satisfy the needs of the modern population as the well-known "Khrushchev-era apartments". [7, 10]

Nowadays, Moscow is implementing a redevelopment program for abandoned industrial zones, which is financed by the city budget. As a part of it, it is planned to create the Technological Park "Stroitelny" at one of the former industrial zones so that in the future professional training of construction personnel will be carried out on its territory. Thus, from the very task posed to the emerging technology park, it is clear that there is no development of innovative technologies, building materials, etc. for the construction industry, and we are talking about the competencies of future personnel for construction enterprises. At the same time, in Russia (in particular in Moscow), there are universities that have been training personnel for the construction industry for decades. For example, specialized training is given on the basis of the Moscow State University of Civil Engineering, where bachelors, specialists, masters, graduate students and doctoral students graduate in 200 educational programs annually for the provision of the construction industry with qualified workers.

Thus, a number of discrepancies are seen in what is being implemented today and what is planned to be achieved. On the one hand, the state is interested in improving the quality of life of the population. On the other hand, quality cannot be improved only by increasing the number, if we talk about the same number of square meters per inhabitant. The development strategy of the construction industry and changes in the regulatory framework affecting the construction sector suggest a decrease in the number of developers, their enlargement with a simultaneous increase in the volume of housing being built. That is, the load on developers will increase as they adapt to new working conditions in the market in connection with the introduction of settlements through escrow accounts. At the same time, the creation of a technology park for training professional personnel for the construction industry does not seem rational, since there are specialized universities that fully provide the industry with highly trained personnel who meet the required competencies. An entirely reasonable solution could be to increase the number of places for studying in construction universities, while creating technology parks, the purpose of which would be the creation and implementation of innovative construction technologies and new building materials in construction practice in cooperation with construction universities. With this scenario, it is possible to obtain the maximum effect: to achieve an increase not only in the volume of construction, but also in improving the quality of future development through the development of new technologies in construction, the use of materials that are more advanced in quality, and to obtain the necessary number of professional construction workers who are practical and knowledgeable about new technology.

Again, if we turn to the history of the post-war years, when the USSR had great growth in both industrial and housing construction, we will see that the big problem of that period was ensuring the production of the required building materials in the right volumes [7]. Thus, today the task of bringing enterprises producing building materials and components for construction to the state in which they can ensure the planned growth in housing construction volumes is clearly becoming relevant. This requires the modernization of production, their expansion and the provision of the necessary qualified personnel. According to the author, it would be advisable to combine the processes of modernization and expansion with the innovative component, and for this, inter alia, the creation of a basis for the possibilities of innovative activity is required. Thus, it is proposed to consider the possibility of creating specialized technology parks on the basis of enterprises engaged in the production of building materials and related components, using the research potential of 
specialized construction universities and involving their future graduates, students of construction specialties in joint innovative projects.

The second obvious problem, which was acute in the post-war period and which can be repeated in the current realities, is a very serious shortage of workers at construction sites. Today, at a time when the level of qualification and the availability of the required competencies come to the fore, and high demands are placed on workers [2], the problem of ensuring the construction process with an increase in construction volumes is becoming increasingly important. It is obvious that graduates of universities of construction specialties will be in demand, and their shortage will probably be observed in the next few years. Therefore, to prevent a shortage of labor resources, it would be advisable today to increase the enrollment of students in leading construction universities, taking into account the growing demand. Again, if at the same time it is possible to ensure their participation in innovative projects in the construction industry on the basis of the technology parks proposed for creation, in a few years it will be possible to get not just specialists with the set of required competencies, but that labor force that will be able to develop the construction industry to a whole new level, increasing the quality of housing construction, being able to create and use new construction technologies, innovative materials and structures, etc.

As global practice shows, radical changes in any areas of the economy always require active state intervention: in the legislative aspect, financial, organizational and many others. In the construction industry, it would be impossible to deal with the proposed changes without its help. However, it should be noted that government officials and investors have markedly different goals of creating technology parks, which leads to an imbalance of their development. The business aims to maximize the effect when investing minimal resources, and this approach is interesting for investors, while officials put forward high demands on potential residents, since they are ready to provide them with financial benefits and other advantages to create an enabling environment for creating high-tech production.

In total, three main goals of creating technology parks have historically been distinguished:

1. as an instrument of regional development;

2. for the innovative development of the region by starting the process of forming a technological cluster;

3. to generate innovation.

Thus, there is a task not only to draw attention to the need of solving emerging problems in the construction industry and the possibility of their complex solution by creating and developing specialized technology parks with their close interaction with relevant universities, but also to find a compromise between the interests of government and business in these matters.

\section{Results}

In the construction industry, an exacerbation of several significant problems is obvious in the next few years:

- lack of professional personnel;

- unpreparedness of enterprises manufacturing building materials for a significant increase in output;

- lack of building materials of the required quality.

It is obvious that changes in the industry will lead to even greater problems if timely measures are not taken to eliminate them. The author revealed that today there are no technology parks whose activities would be aimed at developing innovations in the construction industry along with how the technology park is being built, which in the future 
is planned to become an educational platform for training personnel for the construction industry. It is proposed to increase enrollment in specialized universities that train professional personnel for the construction industry; create technology parks on the basis of enterprises manufacturing building materials in order to form an innovative focus on the construction industry and provide students with the opportunity to participate in innovative projects of these technology parks.

\section{Conclusion}

Putting the proposals made by the author into practice will make it possible to increase the socio-economic level of development due to the faster and less laborious process of introducing innovative solutions. Taking into account the identified problems of the construction industry and the quick prevention of their aggravation will lead to lowering costs, including economic, improving the quality of construction and achieving targets with the greatest efficiency.

\section{References}

1. Decree of the President of the Russian Federation No. 642 dated 01.12.2016 "On the Strategy for the scientific and technological development of the Russian Federation"

2. Federal Law "On the independent assessment of qualifications" dated 03.07.2016 No. 238-FZ

3. Government Resolution of the Russian Federation dated 02.05.2013 No. 736-r "On approval of the Concept of the federal target program "Research and development in priority areas for the development of the scientific and technological complex of Russia" for 2014-2020"

4. Decree of the Government of Moscow of April 1, 2008 No. 247-PP "On the territories of industrial zones of the city of Moscow (second stage)"

5. GOST 56425 - 2015 National Standard of the Russian Federation "Technology parks. Requirements"

6. V.S. Vlasenko, Technology parks in the infrastructure for supporting innovative business: global and Russian aspects. Theoretical and practical aspects of the development of modern science: proceedings of International (correspondence) scientific and practical conference, pp. 73-82 (2017)

7. S.A. Vlasov, Housing construction in the post-war years (1946-1957). Russia and AsiaPacific Region, No. 2 (2007)

8. I.B. Efanova, Standards and quality, 1, 54-59 (2018)

9. Technology parks of the world: organization of activity and comparison / ed. V.A. Barinova. - M.: Delo, p. 182 (2012)

10. O.A. Ogorodnikova, Mass housing construction in the history of Soviet everyday life. Universum: social sciences, No. 3 (44) (2018)

11. M. Raunio, N. Nordling, M. Kautonen, P. Rasanen, Foresight and STI Governance, 12, No. 2, pp. 62-76 (2018) DOI: 10.17323/2500-2597.2018.2.62.76

12. I.V. Turitsyn, G.A. Simonyan, Modern scientific thought, No. 1, pp.139-153(2018)

13. https://russiaindustrialpark.ru 